\title{
Modeling of ERP Practical Skills Online Intelligent Assessment System
}

\author{
Ruohui Wang and Jimei $\mathrm{Li}^{*}$ \\ School of Information Science, Beijing Language and Culture University, Beijing, China \\ ${ }^{*}$ Corresponding author
}

\begin{abstract}
In recent years, the ERP practical skills have been developed rapidly worldwide in terms of teaching, testing, competing and training. However, there are still some deficiencies in the existing automatic assessment system. According to the characteristics of ERP system, this paper designs the overall system framework, the system function modules and the assessment flows. These works aim to build a model of online intelligent assessment system for ERP practical skills, so as to develop an ERP practical skills assessment system which can cater for the actual demands.
\end{abstract}

Keywords-ERP; practical skills; online intelligent assessment; system modeling

\section{INTRODUCTION}

Enterprise resource planning (ERP) is the main component of enterprise informatization. With the development of information technology, the enterprises' demand of ERP practical and the qualified personnel is increasing. At present, the mainstream ERP software which focus on personnel training are Yonyou and Kingdee ERP in China, as well as SAP of Germany. Based on the Yonyou ERP software, Seentao Technology Co., Ltd has cooperated with more than 2,700 universities and training institutions to train the potential personnel. So far, a number of trainees have worked for 2.6 million informatized enterprises [1]. Kingdee International Software Group Co., Ltd, or Kingdee, has built the ERP laboratories, the comprehensive training bases and the innovation and entrepreneurship centers in over 1000 colleges and training institutions of 54 cities [2]. The SAP university alliance has supported more than 3200 education institutions in over 111 countries or regions and it has incorporated the latest SAP technology into teaching [3].

In addition, the influence of the skills competitions or certifications based on ERP software has been enlarging rapidly as well. Here takes the Yonyou ERP-U8 software as an example. There are two major competitions. One is the Competition of Accounting Skills (Accounting informatization) held by Ministry of Education, the other is the "Seentao Cup" National Accounting Information Technology Competition organized by Ministry of Industry and Information Technology. Both of them are held once a year with up to a million students.

To sum up, teaching, testing, competing and training of ERP software have developed rapidly in recent years. Since ERP software does not have the function of automatic assessment for teaching and learning, it is necessary to develop an independent assessment system.
The literatures indicate that the mainstream research work of ERP skill assessment can be classified into two categories. The first one is to change operation questions into objective ones. The second one is to ask the examinee to operate in a real ERP environment. In the latter case, the automatic assessment is accomplished by an independent assessment system. However, apart from Yonyou, the other companies, such as SAP and Kingdee, have not yet developed the suitable assessment system. Besides, the existing assessment system has plenty of defects, such as the large workload, not supporting the multi-strategies of answers, not supporting online assessment and inaccurate automatic grading. As a result, a large number of ERP skills assessments are either marked manually or changed into objective questions for grading.

Aiming to solve above issues, this paper innovatively constructs the framework model of the ERP practical skills online intelligent assessment system, in the case of students operating locally as well as the result data being stored locally. It lays the foundation for developing the ERP practical skills assessment system which can better meet the actual needs.

\section{RELATED WORKS}

The ERP practical skills assessment is a kind of IT skills automatic assessment. It is also a key and difficult point in the computer-aided assessment [4-11]. The research status of this topic can be presented from two aspects.

\section{A. General IT Skills Assessment System}

Currently, the IT skills assessment system can be divided into two categories. One requires the examinee to operate in the real software environment, while the other asks for them to conduct in a virtual software environment.

1) The assessment system of IT skills based on real software: In terms of this type of assessment system, Roy Dowsing and Steward, et al, from University of East Anglia, United Kingdom, developed the computer aided assessment systems of word processing and spreadsheet, and named them Word-Task and SpereadTask [12]; XU Jun, Liu QuanBo and HE Kekang, from Beijing normal university, have developed a set of complete systems of IT skills assessment named iTAS and the mentor system for IT skills training named iTutor [6-10]; Aiming at the operation of webpage production, LI Juan and SUN Bo realized an automatic assessment system [13]; JIN Bingyao, MA Yongjin, LUO Hongbo and WU Zhangxing, from Zhejiang Normal University, developed the certificate rating system for IT qualification of primary and middle schools in Zhejiang 
province. They also made a point that an assessment system needs to be accurate first, and then to have high independence and strong adaptability [14]. Based on that, WANG Yifei has designed and realized a system of computer-assisted assessment based on network cooperative [4,5].

This paper aims at ERP practical skills assessment system. As a basic software of enterprise informatization, ERP is an integrated system of enterprise's resources. Therefore, there are essential differences between ERP practical skills assessment and the general IT skills assessment. (1) ERP practical skills assessment pays more attention to the enterprise business requirements, which should not restrict operation paths. (2) The scoring objects of ERP practical skills assessment refer to the data tables, data records and data fields in the ERP database (i.e., account set), which means they are various and complex. (3) ERP practical skills assessment is characterized by multistrategies of solving problems. (4) Each test question of ERP practical skills assessment represents a business of the enterprise. Due to the strong sequential relationship among multiple businesses, the data of corresponding questions are closely associated, and the relevant impact is hard to eliminate.

2) The assessment system based on virtual simulation: Using the virtual simulation technology, American Testing Authority Inc., or ATA, developed an automatic assessment system for IT skills named DST, or Dynamic Simulation Technology. The system provides a virtual interactive assessment environment for the examinees, which is similar to the real software environment [15]. Due to the complex and diverse functions of ERP, it is hard for the ERP skill assessment based on virtual simulation to set test questions or be simulated. Therefore, it has been out of the market at the moment.

\section{B. ERP Practical Skills Assessment System}

The current ERP practical skills assessment systems can be divided into two categories according to the different techniques.

1) Converting the test questions into objective ones: In view of the introduction to the SAP ERP course, GUO Xinshun, from Shanghai Institute of Foreign Trade, and YANG Kun, from Beijing SAP Software System co., 1td., developed an automatic assessment system by turning the operation tests into the fill-inthe-blanks problem [16]. According to the interview of the authors, this method has always been using for ERP teaching assessment in Shanghai Institute of Foreign Trade. Moreover, the Ability Center of SAP University is preparing to promote it in every school using SAP software for teaching. At present, the automatic assessment of SAP practical skill pauses in this stage. But this kind of assessment system cannot assess the actual operation ability of examinees.

2) Independent assessment systems: At present, the mainstream assessment system is based on the C/S framework and it is used only for Yonyou ERP accounting skill assessment [17]. Figure 1 is the operation flow chart of the existing assessment system.

As can be seen from Figure 1, there are some disadvantages of the existing system: (1) not supporting automatically setting marking criteria, (2) only supporting the accounting informatization's business, (3) not supporting multi-strategies of answers, (4) the high risk of leakage of the account set with correct answers, (5) not supporting online assessment, and (6) not supporting personalized feedback.

In conclusion, although the development of IT skills automatic assessment system is mature enough, it is still necessary to design and develop an independent assessment system of ERP practical skills because of its particularity. The existing ERP practical skills assessment systems can meet the basic needs of teaching, testing, competing and training of ERP practical skills. However, due to the major defects in the system framework, it is necessary to model the system for laying a foundation for the development of online intelligent assessment system for ERP practical skills.

\section{DATA Processing MOdE OF ERP SOFTWARE}

The development of ERP practical skills online intelligent assessment system relies on the data processing mode of enterprise ERP system. In terms of different data processing methods, there are differences in framework of assessment systems. According to the framework of ERP software (e.g., teaching version) and the storage location of its answer data, there are two kinds of data processing methods. One is the students operating locally and the result data being stored locally (e.g., Yonyou ERP), the other is the students operating locally but the answer data is centralized stored in the cloud (e.g., SAP). Detailed Analysis is as follows.

\section{A. Different Amount of Data}

As a fundamental software for the enterprise's informalization, ERP is an integrated system of enterprise's resources. The outcomes of information processing are stored in the account set (i.e., database). The database of ERP system storing and processing data locally is located in the local computer. This means that the data in each database contain only the results of the ERP system operation of the corresponding local computer user. However, the database of ERP system storing and processing data in the cloud is, namely, located in the cloud, which stores all the answer data of multiple users of multiple local computers. This results in the data amount in a cloud database is much larger than that in a local database.

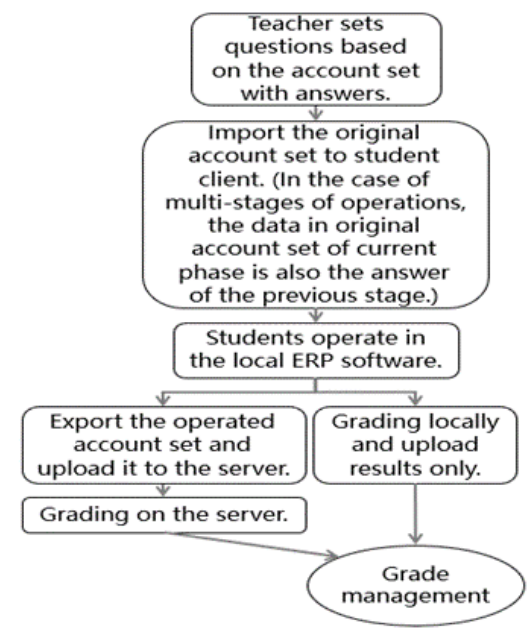

FIGURE I. OPERATION FLOW CHART OF THE EXISTING TEACHING AND TESTING SYSTEM. 


\section{B. Different Complexity of Data}

Users who can access the local database are constrained by the local computer permission, so the data operations are simple. On the contrary, the cloud database allows access to a larger number of users. That is, in an ideal world, a cloud database can support unlimited concurrent users. Multiple users will frequently perform database operations during the same period of time. Therefore, the data stored in the cloud database is diverse and complex.

\section{Different Methods of Obtaining Informatization Data}

The local database is on the local computer, so that the local database will be accessed directly for extracting assessment data. Take Yonyou ERP-U8 as an example. Its supporting local database is SQL Server. With user name and password, a visual tool can be used to inspect the database structure and data storage situation. Thus, the data storage characteristics of ERP system can be analyzed, which helps for the design and development of intelligent assessment system. In contrast, the cloud database is a lot more complicated. (1) The cloud database is difficult to be visually accessed by users, so learning its database structure is more difficult. (2) Due to the large amount and high complexity of cloud data, it is a hard work to extract the assessment data. (3) Because the cloud database supports concurrent user operations, its encryption level is higher. Therefore, when extracting the assessment data, it is necessary to use the corresponding interface for database operations.

In general, the distinctions between the two data processing methods (i.e., the students operating locally and the result data being stored locally, and the students operating locally but the answer data is centralized stored in the cloud) are reflected in different data amount, different data complexity and different data obtaining methods. Therefore, the system model and function modules of ERP practical skills assessment system and its data storage structure based on data model should be different as well.

\section{MODELING OF ERP PRACTICAL SKILLS ONLINE INTELLIGENT ASSESSMENT SYSTEM}

Take the date processing method that students operating locally and the result data being stored locally (i.e., Yonyou ERP-U8) as an example. This paper constructs a model of ERP practical skills online intelligent assessment system. Here is the detailed description of the assessment system in the aspects of the principles of system modeling and the design of system framework.

\section{A. Principles of System Modeling}

There are five principles of system modeling for ERP practical skills online intelligent assessment. (1) Based on the data storage characteristics of ERP system, the system model should be constructed to cater for the corresponding functional requirements, such as reducing workload of teachers and supporting flexible measurement range, etc. (2) The system model has to meet the demands of all system users (i.e. administrators, teachers, students and experts). (3) Aiming to the practical skills assessment of Yonyou ERP-U8, it is more secure to install client on local computer because its SQL Server database can be accessed in a local computer. (4) In order to cater for teaching, testing, competing and training of ERP practical skills, assessment system should not be limited by LAN. In other words, the assessment system is supposed to support a large number of concurrent users online. Therefore, the system is designed on the basis of the framework patterns mixing C/S and $\mathrm{B} / \mathrm{S}$. (5) It is necessary to reasonably divide the system functions so as to reduce the load on the server and improve its running speed.

\section{B. Design of System Framework}

Based on the design principles of online intelligent assessment system for ERP practical skills, the framework of this assessment system will be designed from three aspects: the overall system framework, the system function modules and the assessment flows.

1) Design of overall system framework: Figure 2 shows the overall framework of ERP practical skills online intelligent assessment system. The application system can fall into three parts: the presentation layer for display logic section, the application layer for transaction processing logic section and the data layer for data processing logic section.

a) Presentation layer is used for user interaction: Because this ERP practical skills online intelligent assessment system is designed on the basis of the framework patterns mixing C/S and $\mathrm{B} / \mathrm{S}$, the presentation layer of the system is reflected by the webpage (i.e., the browser) and the client. More specifically, the webpage includes the teacher webpage, student webpage, expert webpage and administrator webpage while the client consists of teacher client and student client.

b) Application layer is used for the specific calculating and data processing: Application layer belongs to the application service of the sever in B/S framework, whereas it is a part of client in $\mathrm{C} / \mathrm{S}$ framework. In this assessment system, the application layer mainly deals with the transactions, such as making marking criterion, composing exam paper, scoring, grading, giving feedback and marking data for scoring, etc. In particular, scoring, grading and giving feedback can be carried out either in the application server or in student client after the module integration. And the transactions like marking data for scoring is processed in teacher client.

c) Data layer is used for database query, modification and update, etc.: Data layer of this assessment system is represented by database on the server and database of client. Database on the server is the main part of this assessment system database, which contains all the data tables of this system. Database of client is classified into teacher client database with the data tables related to the expert knowledge and student client database with the data tables needed for extracting data for scoring. The data tables in client database are all downloaded from the server database and used to support the transactions in the client application layer. It will help alleviate the load on the server. 


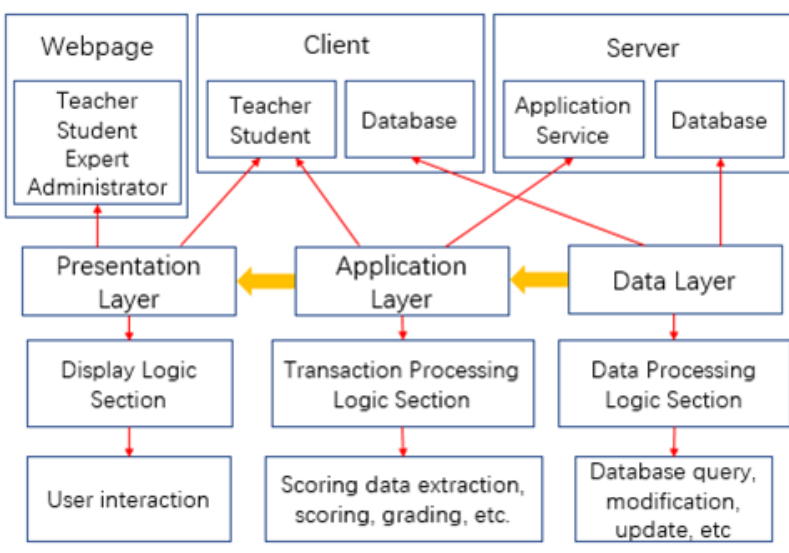

FIGURE II. THE OVERALL FRAMEWORK DIAGRAM OF ERP PRACTICAL SKILLS ONLINE INTELLIGENT ASSESSMENT SYSTEM

2) Design of system feature modules: According to the demands of users and its deployment location, ERP application skills online intelligent assessment system can be split into six subsystems: teachers webpage, teacher client, student webpage, student client, expert webpage and administrator webpage.

Figure 3 is the function module diagram of ERP practical skills online intelligent assessment system. It gives the functional modules corresponding to each subsystems of the whole assessment system. The functions of each subsystem are described in detail below.

a) Teacher webpage: The functions of teacher webpage contain test question management (e.g., browsing the test question bank and adding, deleting or changing test questions), exam paper management (e.g., browsing or editing the exam papers and compositing exam papers), exam class management (e.g., browsing, adding, deleting or changing the exam class and designating the exam users) and grade management (e.g., browsing the students' grade and giving feedback).

b) Teacher client: Teacher client is used for querying test questions and submitting the original operated data.

c) Student webpage: In student webpage, the exam users can query the information of exam class, submit the answer data for scoring and get their grade and feedback of certain exam class.

d) Student client: The major functions of student client include querying exam class (i.e., checking the information such as exam way, allowed answer numbers, etc.) and submitting the operated data.

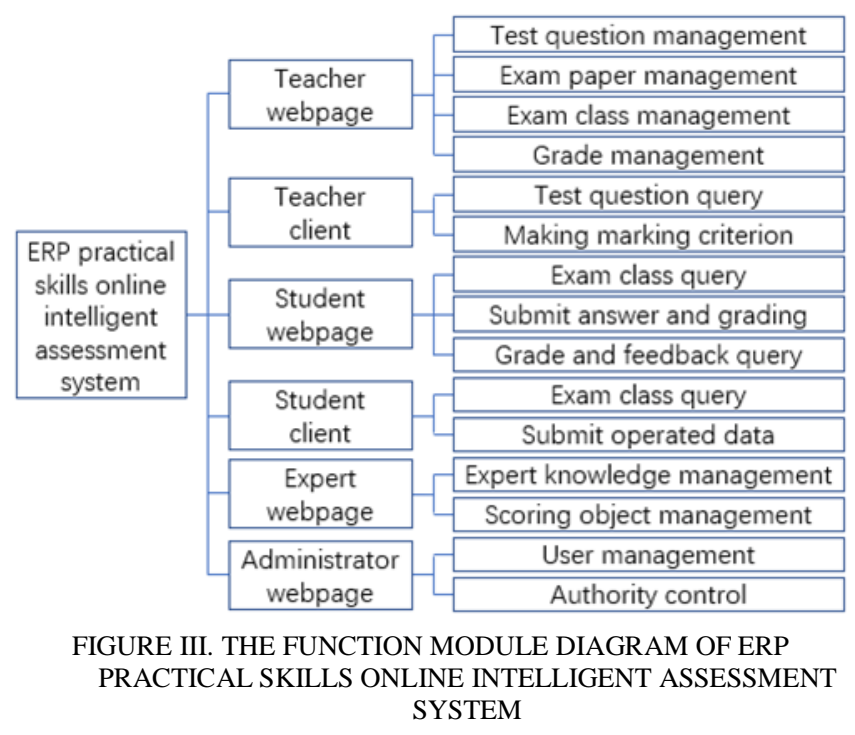

e) Expert webpage: Experts use expert webpage to do the expert knowledge management and the scoring object management such as adding, deleting or editing the expert knowledge and scoring objects.

f) Administrator webpage: Administrator webpage is used for system user management and control the users' authority to the system.

3) Design of assessment flows: The assessment process of ERP practical skills online intelligent assessment system can be interpreted from two perspectives: operation process and data flow. Figure 4 is the operation flow chart of ERP practical skills online intelligent assessment system. Figure 5 is its data flow chart.

As shown in Figure 4, the complete operation steps of the online intelligent assessment system for ERP practical skills are as follows: (1) Experts edit and improve the expert knowledge to satisfy the follow-up assessment. (2) Teachers set test questions. After editing the information of test questions and account set, teachers have to extract the original data and operated data through client and submit the data to the server. (3) Teachers composite the exam papers. A main exam paper consists of one or more sub exam papers, and a sub exam paper contains one or more test questions. Thus, teachers choose test questions and sub exam papers as needed. (4) Teachers publish exam class. In this step, teachers edit the exam class information for a main exam paper, and then publish it. At the same time, the corresponding data collecting rule is generated on the server. (5) Teachers designate the exam users (i.e., students), which allows the examinees to query the exam class information and take the exam. (6) Students query the exam class information. Students browse the exam requirements from the student webpage and take the exam as required. (7) Students answer the test questions. Students operate on ERP-U8 software while running the student client. Following the exam requirements, students submit the operated data by client after they have done the operations. (8) Students submit the operated data. Students confirm their submission of the operated data in student webpage. (9) Server marks the operated data submitted by students, calculates the exam grades and generates the feedback. (10) Students query 
their grade and feedback. Students check their grades and detailed feedback on student webpage. By the way, teachers can view student grades and comments on teacher webpage as well.

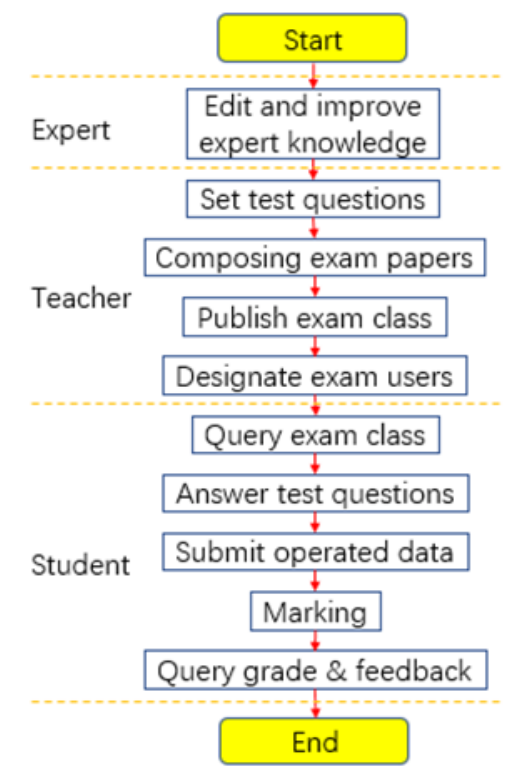

FIGURE IV. THE OPERATION FLOW CHART OF ERP PRACTICAL SKILLS ONLINE INTELLIGENT ASSESSMENT SYSTEM

As shown in Figure 5, the data flow of ERP practical skills online intelligent assessment system involves data communication among databases. These databases include three databases of this assessment system (i.e., the server database, the teacher client database and the student client database), as well as local account sets of ERP-U8 software (i.e., database). The data flow of the assessment system will be explained combining the assessment operation process. (1) At the beginning of the assessment, the expert manages expert knowledge, and the data flow to the server database through the expert webpage. When the teacher sets test questions, the data flow to the server database through the teacher webpage. (2) Before the teacher submits the operated data, the data tables related to this procedure is supposed to be downloaded from the server to the teacher client. At this point, the data flow from the server database to the teacher client database. (3) When the teacher is setting the correct answers of test questions, it is necessary to extract the data from the ERP-U8 database on the teacher's computer according to the expert knowledge and store them in the teacher client database for the data preprocessing. Therefore, the data flow is from the local account set (i.e., database) in teacher's computer to the teacher client database. (4) Before the teacher composites exam papers, the operated data has been uploaded to the server, so the data flow to the server database from the teacher client database. When compositing exam papers, publishing exam class and designating exam users, the data are changed only within the server database by interfacing with teacher webpage. The step of students viewing the exam class information is, in fact, the process of querying the data in the server database and display it on the student webpage. (5) Before the students answer the test questions, the data tables related to this procedure need to be downloaded from the server to the student client. At this moment, the data flow from the server database to the student client database. (6) When the students submit their operated data. it is requisite to extract the data from the ERP-U8 database on the student's computer according to the data collecting rule and store them in the student client database. Therefore, the data flow is from the local account set (i.e., database) in student's computer to the student client database. (7) The process of submitting the operated data of the students is to transfer the data from the student client to the server, that is, the data flow to the server database. Marking the exam paper on the server is along with passing the relevant data to the application server. After obtaining the results, it will be stored in the server database. This whole process should not involve other databases. The step of students or teachers checking the grade and feedback is the process of displaying the data of server database on the webpage. (8) At the end of the assessment process, the data in server database can be cleared as needed.

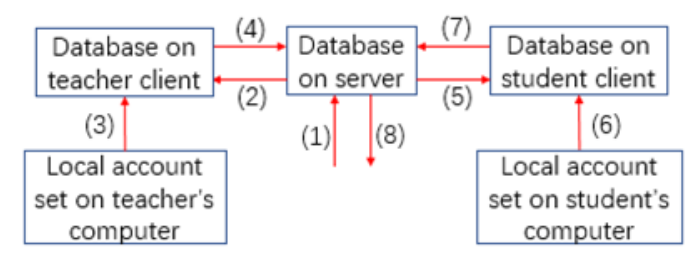

FIGURE V. THE DATA FLOW CHART OF ERP PRACTICAL SKILLS ONLINE INTELLIGENT ASSESSMENT SYSTEM

To sum up, this paper constructs a model of online intelligent assessment system for ERP practical skills. The overall framework of this system is mixing $\mathrm{C} / \mathrm{S}$ and $\mathrm{B} / \mathrm{S}$, which supports the online assessment. The system function modules are distributed in six subsystems (i.e., teachers webpage, teacher client, student webpage, student client, expert webpage and administrator webpage). After the functional requirements of all system users is satisfied, the server load is relived and the information security is improved as well. The assessment flows can be explained by operation process and data flow. The two are based on functional modules and interdependent, which support the automation and intelligence of the assessment system.

\section{SUMMARY}

In recent years, the ERP practical skills have been developed rapidly worldwide in terms of teaching, testing, competing and training. However, there are still some deficiencies in the existing automatic assessment system. According to the characteristics of ERP system, this paper designs the overall system framework, the system function modules and the assessment flows. These works aim to build a model of online intelligent assessment system for ERP practical skills. The main features and functions of the model are as follows: (1) This system model caters for the corresponding functional requirements, such as reducing workload of teachers. (2) This system model meets the demands of all system users (i.e. administrators, teachers, students and experts). (3) This system model adopts to install client in local computer in the view of security. Meanwhile, considering the whole system, data processing in the client reduces the load on the server. (4) This system model designs on the basis of the framework patterns mixing $\mathrm{C} / \mathrm{S}$ and $\mathrm{B} / \mathrm{S}$ which allows the assessment system to support a large number of concurrent users online. Moreover, it 
caters more for teaching, testing, competing and training of ERP practical skills.

The following research can be stated from the two aspects: (1) A set of algorithms of intelligent assessment. These include: a set of algorithms related to setting test questions, compositing exam papers and the answering step, such as collecting and marking data for scoring, etc.; a set of algorithms related to intelligent marking, such as optimal matching between the records of result that is submitted by examinee and the records of answer that is provided by examiner and calculating the exam paper scores, etc.; a set of algorithms related to personalized learning analysis, such as plagiarism detection and job skill analysis, etc. (2) Extend the application scope of the assessment system model. Learn more about the ERP data processing mode that the students operating locally but the answer data is centralized stored in the cloud (e.g., SAP), and construct a model of assessment system to meet the relevant requirements.

\section{ACKNOWLEDGMENT}

This research project is supported by Science Foundation of Beijing Language and Culture University (supported by "the Fundamental Research Funds for the Central Universities") (No: 17ZDJ02, 17PT01, 16YJ030001, 17YJ0304, OTP201607), and by Computer Foundation Education Research Institute of National Colleges and Universities (No: 2018-AFCEC-177).

\section{REFERENCES}

[1] Seentao Technology Co., Ltd. Introduction. [EB/OL]. [2018-0211]. http://www.seentao.com/page/index/name/gyxd. [in Chinese]

[2] Kingdee International Software Group Co. Ltd. Kingdee education industry solutions.
[EB/OL]. [2018-02-11]. http://www.kingdee.com/solutions/industry/edu. [in Chinese]

[3] SAP. Introduction of SAP university alliance. [EB/OL]. [201803-04]. https://www.sap.com/china/training-certification/ universityalliances.html. [in Chinese]

[4] WANG Yifei. Research on the system of computer-assisted assessment in IT skills based on network cooperative [D]. Jinhua: Zhejiang Normal University, 2011. [in Chinese]

[5] WANG Yifei. The Design of a Network Automatic Scoring System for IT Skills[J]. Computer Knowledge and Technology, vol. 10, pp. 2270-2272, 2014(10). [in Chinese]

[6] HE Kekang and XU Jun. The New Development of Research on Computer Assisted Assessment(CAA) [J]. Open Education Research, vol.11, pp. 78-83, 2005(02). [in Chinese]

[7] XU Jun, LIU Quanbo and HE Kekang. New field of CAA research -- IT skills assessment automation (part one) [J]. eEducation Research, pp.3337, 2002(01). [in Chinese]

[8] XU Jun, LIU Quanbo and HE Kekang. New field of CAA research -- IT skills assessment automation (part two) [J]. eEducation Reaearch, pp.4448, 2002(02). [in Chinese]

[9] XU Jun and LIU Quanbo. IT Skill Automated Testing and Assessment:Theory, Technologies and Applications[M]. Beijing: Science Press , 2001. [in Chinese]

[10] XU Jun. The Theory of Automated Skills Testing and Assessment and its Application [D]. Beijing: Beijing Normal University, 2001. [in Chinese]

[11] XIONG Yuzhen and PENG Dequan. Current Status and Development of Computer-assisted Chinese Characters Assessment[J]. China Examinations, pp.20-26, 2013(09). [in Chinese]

[12] LIANG Huina. Design and implementation of the Computer Basic Applications Course Online Test System[D]. Guangzhou: Sun Yat-sen University, 2011. [in Chinese]
[13] LI Juan and SUN Bo. Study on Skill Assessment Method Based on Marking Criteria and Execution Engine [J]. Computer Applications and Software, vol.29, pp.128-132, 2012(10). [in Chinese]

[14] JIN Bingyao, MA Yongjin, LUO Hongbo and WU Zhangxing. The Formal Deseription of Check Information and its Applications [J]. Computer Science, vol.32, pp.106-107, 2005(01). [in Chinese]

[15] ATA Company. CAA Technologies [EB/OL]. [2018-03-08]. http://ir.ata.net.cn/ irwebsite/ index.php.

[16] GUO Xinshun and YANG Kun. Design of ERP test automatic marking based on the practice [J]. University Education, pp.71-72, 2013(01). [in Chinese]

[17] SowerPower Technology Co. Ltd. Competition system (national vocational skills contest accounting skills competition) introduction. [EB/OL]. [2018-03-07]. http://www.sower.com.cn/index.php?list=5. [in Chinese]

[18] ZHENG Chuansheng. Design of Automatic Test and Judge Based on B/S Architecture [J]. Computer and Modernization, pp.109-111, 2007(12). [in Chinese]

[19] ZHANG Shuili, DONG Juntang and FENG Minna. Design and implementation of MVC-based online examination assessment system [J]. Modern Electronics Technique, vol.38, pp.67-70, 2015(14). [in Chinese]

[20] HAN Zhongyuan, MA Wei, SUN Yuhua, HAN Yong and CUI Shuo. Design and Implementation of the Framework of Small-scale Information Retrieval System Based on SQL Server 2008 [J]. Programming Skills \& Maintenance, pp.44-46\&58, 2010(10). [in Chinese]

[21] QU Zhaoxia and FU Qian. Research on Framework of Automatic Laboratory-skill Assessment System [J]. Application Research of Computers, vol.24, pp.218-219, 2007(5). [in Chinese]

[22] SHI Jiaoli, HUANG Chuanhe, WANG Jing, QIN Kuangyu and HE Kai. Multi-user collaborative access control scheme in cloud storage [J]. Journal on Communications, vol.37, pp.88-99, 2016(1). [in Chinese]

[23] YANG Fan and LI Kuansheng. Analysis of digital library service model based on cloud data base service architecutre [J]. Jiangsu Science \& Technology Information, pp.1-2, 2016(33). [in Chinese]

[24] CAA Center. [EB/0L]. [2018-03-08]. http://www.caacentre.ac.uk/

[25] ZHU Zhanli and WANG Kuisheng. Research on Framework of ERP Software Systems for Small \& Medium-sized Enterprises [J]. Computer Engineering, vol.32, pp.37-38\&44, 2006(12). [in Chinese]

[26] LI Yuyao, Yan Zaigeng, JIANG huiyun, QUAN Lincong, LIN Lin and TAO Canfeng. Research on Objective Question Type in Process For Erp Supply Chain Teaching Evaluation [J]. Computer Applications and Software, vol.34, pp. 128-132,141, 2017(2). [in Chinese]

[27] WU Yunming. Design and Development of the Network Examination and Evaluation System Based on B/S Framework [D]. Qufu: Qufu Normal University, 2005. [in Chinese]

[28] YANG Jiaji and MENG Yanhong. Design and Implementation of the Practice Curriculum Management System Based on the SSH Framework [J]. SOFTWARE ENGINEERING, pp.26-28\&15, 2017(12). [in Chinese]

[29] Chen, Y. Application of Education Information Assessment System Based on UML Framework and J2 Technology in Foreign Chinese Teaching[C]. in 2nd International Conference on Information and Communication Technology for Education (ICTE 2015). 2015. London, UK.

[30] Liu, W. and Q. Yan. Research and Applications of Course System Framework Based on Unit[C]. in 2017 4th International Conference on Education, Management and Computing Technology (ICEMCT 2017). 2017. Hangzhou, China: Atlantis Press. 